\title{
INVESTIGATION OF PIEZOELECTRIC PATCHES PLACEMENT ACCORDING TO THE STRAIN INTENSITY
}

UDC:519.673:539.433

Original scientific paper

https://doi.org/10.18485/aeletters.2020.5.2.2

\author{
Erdi Gülbahçe ${ }^{1 *}$, Mehmet Çelik ${ }^{2}$ \\ ${ }^{1}$ KTO Karatay University, Faculty of Engineering, Mechatronics Engineering Department, Konya, Turkey \\ ${ }^{2}$ KTO Karatay University, Faculty of Engineering, Mechanical Engineering Department, Konya, Turkey
}

\begin{abstract}
:
In active vibration control of the smart structures, the dynamic characteristics directly affect the damping performance; also, the actuators are the important element for the vibration reduction. Therefore, the optimal placement of the actuators/sensors on the structure is the key parameter to enhance the control performance. Within this scope, in this study, the possible optimal placement of piezoelectric actuators/sensors on the cantilever smart plate structure is presented by using mode superposition method. The simple plate and the smart plate are investigated with respect to compare each other according to the modal parameters such as mode shape and natural frequency. The numerical studies based on the finite element analysis are conducted in ANSYS Workbench software. As a result of the study, it is seen that the strain intensity calculations obtained after the mode combination can be used in the layout of piezoelectric actuators. Thus, a fast and practical solution for preparing the basis of optimal actuators/sensors placement is presented.
\end{abstract}

\section{ARTICLE HISTORY}

Received: 27.03.2020.

Accepted: 11.05.2020.

Available: 30.06.2020.

\section{KEYWORDS}

Placement of actuators, piezoelectric, finite element analysis, vibrations, mode superposition

\section{INTRODUCTION}

The vibrations may cause undesirable effects on engineering structures, buildings, reduced service life, or damage to mechanical system components. Moreover, high levels of vibrations and acoustic noises may cause many problems in human living environments such as hearing loss, heart failure, increased stress level, and uncomfortable life condition, etc. In the literature, the vibration control studies for vibration damping and noise reduction have been commonly encountered ranging from the ground, sea and space applications to the nano and micro devices. In this regard, the vibration damping studies of structures which use smart materials go back twenty years and these structures are called as smart structures.

Nowadays, the significant studies are performed to control of noises and vibrations in many applications and industries. The dynamic characteristics of the structure are the key parameter because of affecting the damping performance. Therefore, one of the most important steps is the position of the piezoelectric actuators/sensors on the structure [1].

The researchers used different techniques for the placement of piezoelectric actuators/sensors. The finite element method was used to determine the optimal position of the sensors/actuators for active vibration control. Some researchers have achieved enough and effective results by applying different optimization techniques on the finite element models. Others strengthened their numerical results with experimental studies. Best actuator or sensor locations are determined by the mode shapes of the smart structure [2]. Similarly, in other studies, many optimization applications are presented in a cantilever mounted plate. The simulations show the efficiency of GA (Genetic Algorithm) for these optimization problems [3]. As 
a result of the Biglar's study, it has been shown that damping effect of piezoelectric sensors and actuators may be increased by the most suitable positioning [4]. Similarly, researchers present computationally efficient methods for determining the optimal position of the sensor / actuator pairs for active vibration reduction of flexible structures [5-8].

In this study, the numerical investigations are carried out on a cantilever smart plate to determine the best possible locations of the actuators/sensors for active vibration control. This paper focused on two structural models. One of them is a simple plate made of aluminium. The other is a smart plate consist of 100 piezoelectric patches that are bonded on simple aluminium structure. Firstly, the modal analysis is conducted to obtain modal parameters such as mode shapes and frequencies of these two models. Then, the mode superposition method is used to combine modes of the smart structure. As a result of the combination, the voltage response and strain intensity results are used to show possible optimal locations on the smart structure. The all numerical works are carried out in ANSYS Workbench software. As a result of the study, a fast and practical solution for preparing the basis of optimal actuators/sensors placement is proposed.

\section{NUMERICAL MODAL ANALYSIS OF THE SMART PLATE}

A thin aluminium plate with dimensions $555 \times 405 \times 1 \mathrm{~mm}$ is used as the host structure of the smart plate. A hundred piezoelectric patches with dimensions $50 \times 35 \times 0.7 \mathrm{~mm}$ are bonded to the host structure in order to show the voltage responses of the piezoelectric patches (actuators/sensors) after the mode combination analysis. The mechanical properties of the aluminium plate and the piezoelectric properties of the patches are shown in the Table 1. Piezoelectric properties are defined for all patches which are equal interval on the host structure as shown in Fig.1.

The finite element method is used to model the smart structure in the ANSYS workbench software. The all structure is meshed into 15991 elements. The minimum element size is selected as $10 \mathrm{~mm}$. The smart plate is fixed one end as cantilever. Before the modal analysis, ANSYS Coupled Fields extension is installed into the software in order to identify piezoelectric material properties onto the finite model. The finite model that includes the mesh and dimensional properties is shown in Fig.1.
The contact types between the piezoelectric patches and the aluminium plate are selected as piezoelectric contact.

Table 1. Mechanical properties of the smart structure

\begin{tabular}{|c|c|c|c|}
\hline \multicolumn{4}{|c|}{ Aluminum Plate } \\
\hline$\rho$ & $2770 \mathrm{~kg} / \mathrm{m}$ & & \\
\hline$E$ & $69 \mathrm{GPa}$ & & \\
\hline$u$ & 0.34 & & \\
\hline \multicolumn{4}{|c|}{ Piezoelectric Patch } \\
\hline$c_{11}^{E}$ & $123 \mathrm{GPa}$ & $e_{31}$ & -7.15 N/N.m \\
\hline$c_{12}^{E}$ & $76.7 \mathrm{GPa}$ & $e_{33}$ & -13.7 N/N.m \\
\hline$c_{13}^{E}$ & $70.3 \mathrm{GPa}$ & $e_{15}$ & 11.9 N/V.m \\
\hline$c_{33}^{E}$ & $97.1 \mathrm{GPa}$ & $\varepsilon_{11}^{s} / \varepsilon_{0}$ & 930 \\
\hline$c_{44}^{E}$ & $22.3 \mathrm{GPa}$ & $\varepsilon_{33}^{S} / \varepsilon_{0}$ & 857 \\
\hline$c_{66}^{E}$ & $23.2 \mathrm{GPa}$ & $\rho$ & $2800 \mathrm{~kg} / \mathrm{m3}$ \\
\hline
\end{tabular}

In order to show the vibration modes, the first six modes of the smart plate and simple plate are obtained with modal analysis by using the Block Lanczos method in the ANSYS software. According to the numerical results obtained from the first six modes, the natural frequencies of the aluminium plate without piezoelectric patches are $2.762 \mathrm{~Hz}$, $8.853 \mathrm{~Hz}, 17.109 \mathrm{~Hz}, 29.29 \mathrm{~Hz}, 36.505 \mathrm{~Hz}, 48.837$ $\mathrm{Hz}$, respectively. On the other hand, the natural frequencies of the aluminium plate with piezoelectric patches are $3.1174 \mathrm{~Hz}, 9.8625 \mathrm{~Hz}$, $18.558 \mathrm{~Hz}, 33.179 \mathrm{~Hz}, 39.522 \mathrm{~Hz}, 52,522 \mathrm{~Hz}$, respectively. According to the natural frequency results, it appears that piezoelectric patches do not have much effect on the results.

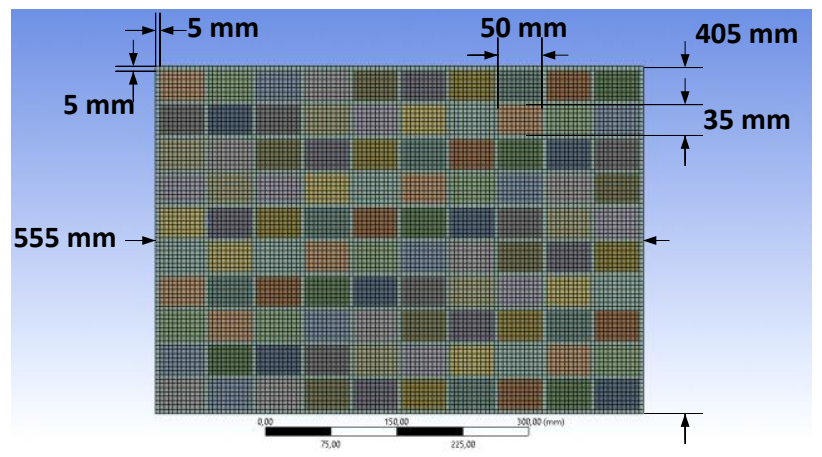

Fig.1. Finite model of the smart plate

The numerical results show that the total effective mass participation factor is the 0.862 (aluminium plate without piezoelectric patches) and 0.876 (aluminium plate with piezoelectric patches) in $+Z$ direction of the structure for first six modes. The total effective mass participation factor should be at least 0.8-0.9 for the selected number of modes. It can be understood that investigation of the first six modes are enough to complete modal analysis. 
The mode shapes of simple plate and smart plate are appeared similar, Fig.2. When the first three modes are examined, it is clearly seen that the 1st and 3rd modes shows the bending movement and the 2nd mode show the torsion movement. Also, stress and strain calculations are considered in modal analysis in order to use in mode combination.

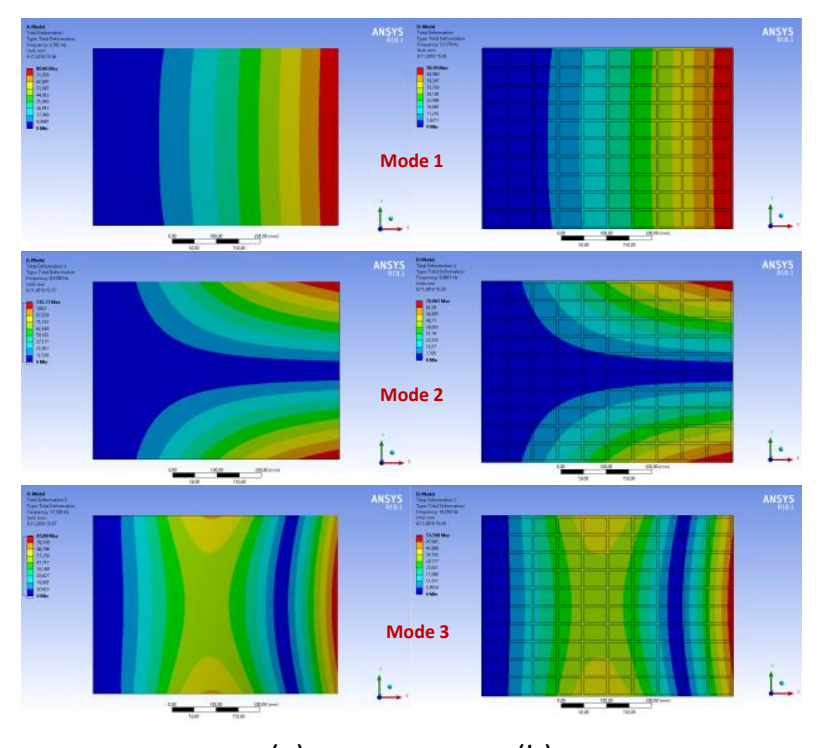

(a)

(b)

Fig.2. Mode shapes for the first three modes; (a) simple plate, (b) smart plate

\section{RESULTS AND DISCUSSIONS}

In ANSYS Workbench software, the design assessment analysis provides the capability of performing a solution combination for a static structural, modal, harmonic response, random vibration, response spectrum, explicit dynamics, or transient structural analysis [9]. Therefore, Design Assessment Toolbox gives an important solution in order to combine modal analysis results according to the mode superposition.

In this study, the results of the completed modal analysis (for first six modes) of the smart plate are superimposed with determined weighting coefficients. Because this paper deals with investigation study, the weighting coefficients are considered as the unit value in the design assessment analysis for each mode. After the mode's combination, the piezoelectric voltages and strain intensity are calculated in the Design Assessment Toolbox.

The voltage responses of the piezoelectric patches are shown Fig.3-a. High voltages have occurred in areas that appear blue. Then, the strain intensity analysis is performed in order to compare with the voltage responses of piezoelectric patches. The strain intensity results are shown in Fig.3-b.

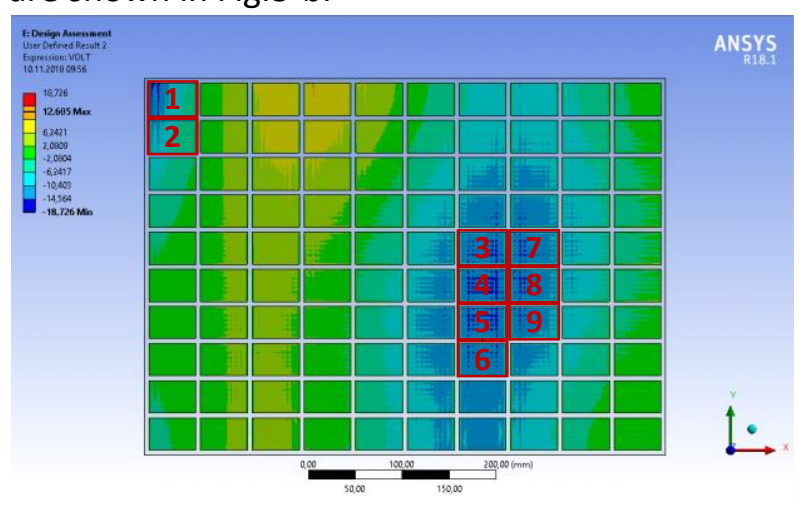

(a)

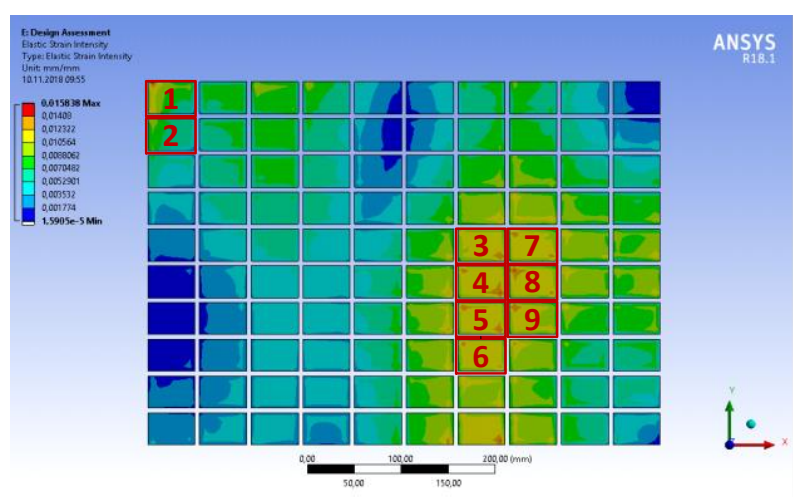

(b)

Fig.3. The possible patch locations; (a) voltage response, (b) strain intensity

As a result of all these numerical analyses, it can be obviously showed that the strain intensity analysis is similar to the voltages analysis. Considering the dynamic characteristics of the structures, it is widely known that the high strain areas obtained according to each mode shape are ideal locations for actuator and sensor placement. It has been interpreted that the high strain areas of the new structural shape, consisting of all modes or a combination of related modes, may also be the ideal location for the actuator and sensor.

Moreover, the possible piezoelectric locations are numbered as shown in Fig.3. These locations show the capability of the voltage produced by piezoelectric patches. It can be concluded that if the patches are used as actuator or sensor, these nine locations show the best observability and controllability performance.

\section{CONCLUSION}

In this study, the mode superposition method is used to combine modes of the smart structure in order to determine the possible optimal 
actuators/sensors locations for active vibration control.

The voltage responses of the piezoelectric patches and the strain intensity responses of the cantilever smart plate are compared with the help of the finite element analysis. It is obviously seen that the strain intensity analysis is similar to the piezoelectric voltage's analysis after the six modes combination. According to the results, instead of piezoelectric modelling studies, which is a laborious task, strain intensity analysis can be performed. Thus, the simpler model can be analysed in less time.

As a result of the study, optimal nine locations are determined according to the high voltage areas or the high strain areas. The best of these nine positions can be selected using different optimization techniques. The knowledge gained from this study will constitute the basis of the future studies.

\section{ACKNOWLEDGEMENTS}

This study was carried out with the smart structure project supported by TUBA (Turkish Academy of Sciences).

\section{REFERENCES}

[1] E. Gülbahçe M. Çelik, Active vibration control of a smart beam by a tuner-based PID controller. Journal of Low Frequency Noise, Vibration and Active Control, 37 (4), 2018: 1125-1133.

https://doi.org/10.1177/1461348418782169

[2] Y. Yaman, T. Caliskan, V. Nalbantoglu, E. Prasad, D. Waechter, Active vibration control of a smart plate, 23rd Congress of International Council of the Aeronautical Sciences (ICAS 2002), 8-13 September, 2002, Toronto, Canada, pp.1-10.

[3] I. Bruant, L. Gallimard, S. Nikoukar, Optimal piezoelectric actuator and sensor location for active vibration control, using genetic algorithm. Journal of Sound and Vibration, 329 (10), 2010: 1615-1635.

https://doi.org/10.1016/j.jsv.2009.12.001

[4] M. Biglar, M. Gromada, F. Stachowicz, T. Trzepieciński, Optimal configuration of piezoelectric sensors and actuators for active vibration control of a plate using a genetic algorithm. Acta Mechanica, 226, 2015: 34513462.

https://doi.org/10.1007/s00707-015-1388-1

[5] L. Sun, W. Li, Y. Wu, Q. Lan, Active vibration control of a conical shell using piezoelectric ceramics. Journal of Low Frequency Noise, Vibration and Active Control, 36 (4), 2017: 366-375.

https://doi.org/10.1177/1461348417744304

[6] A. Loghmani, M. Danesh, M. Keshmiri, M. M. Savadi, Theoretical and experimental study of active vibration control of a cylindrical shell using piezoelectric disks. Journal of Low Frequency Noise, Vibration and Active Control, 34 (3), 2015: 269-287.

https://doi.org/10.1260/0263-0923.34.3.269

[7] K. Bendine, F. Boukhoulda, B. Haddag, M. Nouari, Active vibration control of composite plate with optimal placement of piezoelectric patches. Mechanics of Advanced Materials and Structures, 26 (4), 2017: 1-9.

https://doi.org/10.1080/15376494.2017.1387324

[8] D. Chhabra, G. Bhushan, P. Chandna, Optimal placement of piezoelectric actuators on plate structures for active vibration control via modified control matrix and singular value decomposition approach using modified heuristic genetic algorithm, Mechanics of advanced materials and structures, 23 (3), 2016: 272-280.

https://doi.org/10.1080/15376494.2014.949932

[9] A. W. ANSYS, "18.1 help documentation [db]," Mechanical APDL ANSYS Parametric Design Language Guide. 